Bangladesh J. Bot. 49(4): 927-935, 2020 (December)

\title{
SILENCING OF THE PHYTOENE DESATURASE GENE MITIGATES OXIDATIVE STRESS THROUGH THE ACCUMULATION OF FREE AMINO ACIDS
}

\author{
Md Sarafat Ali ${ }^{1}$ and Kwang-Hyun Baek* \\ Department of Biotechnology, Yeungnam University, Gyeongsan, \\ Gyeongbuk 38541, Republic of Korea
}

Keywords: Free amino acids, Nicotiana benthamiana, Oxidative stress, Phytoene desaturase, Virus-induced gene silencing

\begin{abstract}
Phytoene desaturase (PDS) is a rate-limiting enzyme involved in the biosynthesis of carotenoids, which converts phytoene to zeta-carotene in a two-step desaturation reaction. Transiently blocked carotenogenesis by silencing the PDS gene in Nicotiana benthamiana (NbPDS) using the virus-induced gene silencing (VIGS) technique was used. Silencing of $N b P D S$ induced dwarfism and an albino-type leaf trait in $N$. benthamiana. The NbPDS-silenced leaves accumulated free amino acids in amounts 9.5 -folds greater than those of the $G F P$-silenced control leaves, but contained only $59.6 \%$ of total soluble proteins. When treatment with 10 and $100 \mu \mathrm{M}$ paraquat was carried out to induce oxidative stress, $N b P D S$-silenced $N$. benthamiana demonstrated more resistance at both concentrations compared to the control plants. These data strongly suggest that high concentrations of free amino acids occur because they are inadequately incorporated into proteins of the $N b P D S$-silenced plants, but reduce injury inflicted by oxidative stress even without the assistance of important antioxidants like carotenoids.
\end{abstract}

\section{Introduction}

Plants have evolved to develop a large number of physiological and biochemical strategies to cope with stresses (Liang et al. 2018). All environmental and biotic stresses trigger a generalized oxidative stress in plants (Xie et al. 2019). The stress is induced by over-production and accumulation of oxidative molecules, such as the reactive oxygen species (ROS) including peroxides, superoxide, hydroxyl radical, singlet oxygen, and alpha-oxygen (Kanojia and Dijkwel 2018). Attack of ROS on biological molecules induces deoxyribose oxidation, removal of nucleotides, DNA-protein crosslinking, and strand breakage in the DNA (Halliwell 2006). Particularly, changes in the nucleotides of one DNA strand due to oxidative stress can lead to mismatches with nucleotides of the other strand. This phenomenon can lead to mutations and, in consequence, synthesis of unwanted or damaged proteins within the cell.

The ROS produced extensively in plants due to stresses are scavenged by activating the antioxidative systems, which are categorized into two groups, those with enzymatic and nonenzymatic components (Pandey et al. 2017). The enzymatic components include several antioxidant enzymes, such as superoxide dismutase, catalase, monodehydroascorbate reductase, dehydroascorbate reductase, glutathione reductase, guaiacol peroxidase and ascorbate peroxidase (Abogadallah 2010). Non-enzymatic components comprise a number of low-molecular weight antioxidant compounds, such as carotenoids, tocopherols, ascorbates, glutathione, and phenolic compounds (Soares et al. 2018).

*Author for correspondence: <khbaek@ynu.ac.kr>. ${ }^{1}$ Department of Biotechnology and Genetic Engineering, Bangabandhu Sheikh Mujibur Rahman Science \& Technology University, Gopalgonj 8100, Bangladesh 
Carotenoids belonging to the family of tetraterpenes can function as potent non-enzymic antioxidants in addition to their roles of accessory light-harvesting pigments and precursors for phytohormones. Carotenoids are involved in diverse but critical plant processes, such as photosynthesis, photomorphogenesis, photoprotection, and development (Nisar et al. 2015). Under conditions of oxidative stress, carotenoids are involved in the photoprotection of the reactioncenter chlorophylls against ROS and prevent the formation of chlorophylls with triplet excited states $\left({ }^{3} \mathrm{Chl}{ }^{*}\right)$ in the chloroplasts (Ramel et al. 2013). Stabilization of the plasma membrane against membrane lipid peroxidation is another contribution of the carotenoids towards protective function (Ademowo et al. 2017).

Synthesis of carotenoids takes place from two molecules of geranylgeranyl diphosphate and requires the enzymes phytoene synthase, phytoene desaturase (PDS), and lycopene cyclase (Sun et al. 2018). PDS, an intrinsic membrane protein found in both chloroplasts and chromoplasts, is the rate-limiting molecule in the biosynthesis of carotenoids (Brausemann et al. 2017). It converts phytoene to zeta-carotene in a two-step desaturation reaction and silencing of the PDS gene in higher plants produces photobleaching symptoms in the leaves (Srinivasan et al. 2017).

Free amino acids accumulate in plants as compatible solutes under stressful conditions. The accumulation of free amino acids can increase the ability of the plant cells to retain water without affecting their normal metabolism. The free amino acids, either directly or indirectly, stabilize the quaternary structure of proteins and membranes protecting them against the adverse effects of drought, high salinities and extreme temperatures (Sakamoto and Murata 2000).

The potential protective roles of the PDS gene in response to abiotic and multi-stresses were demonstrated in Nicotiana benthamiana (Anaraki et al. 2017). However, there is no report on the roles of the PDS gene in the accumulation of free amino acids and protection against oxidative stress. In the present study, virus-induced gene silencing (VIGS) to silence the PDS gene in $N$. benthamiana (NbPDS) was applied and measured the differential accumulation of free amino acids induced by it. Furthermore, the roles of accumulated free amino acids were identified by measuring their tolerance to oxidative stress induced by paraquat treatment.

\section{Materials and Methods}

Seeds of Nicotiana benthamiana were sown and the plants were grown in plastic pots $(12 \mathrm{~cm}$ diameter $\times 10 \mathrm{~cm}$ height) containing $70 \%$ coco peat, $17 \%$ peat moss, $5 \%$ zeolite, and $8 \%$ perlite. The plants were regularly watered and grown under fluorescent lights at $120 \mu$ Einstein $/ \mathrm{m}^{2} / \mathrm{s}$ with a regime of $16 / 8 \mathrm{hrs}$ light/dark cycles at $22 \pm 2^{\circ} \mathrm{C}$ in the walk-in chamber at the Molecular Physiology lab in the Department of Biotechnology, Yeungnam University, Republic of Korea.

For transient silencing of the NbPDS gene, Agrobacterium with a VIGS construct of $369 \mathrm{bp}$ nucleotide sequence derived from the N. tabacum PDS gene (NCBI accession No. AJ616742) was inoculated into the leaves of $N$. benthamiana (Hasan et al. 2014). The silencing of NbPDS was confirmed by conducting a semi-quantitative RT-PCR using the appropriate primer sets (Ali et al. 2015). N. benthamiana leaves were also inoculated with a construct of the green fluorescent protein $(G F P)$ gene as the control. The GFP control construct was prepared by inserting a $983 \mathrm{bp}$ nucleotide sequence from the GFP gene of Aequorea victoria (Hasan et al. 2014).

The leaves of $N$. benthamiana were analyzed for the contents of free amino acids and total soluble proteins, as described by Ali et al. (2015). The levels of free amino acids and total soluble proteins were analyzed using the leaves that were 6 positions above those infiltrated for $G F P$ - or $N b P D S$-silencing in the respective $N$. benthamiana plants. To observe the effects of oxidative stress on the NbPDS-silenced plants, 28-day-old infiltrated plants were sprayed thoroughly with different concentrations of paraquat (methyl viologen, 1,1'-dimethyl-4,4'-bipyridinium dichloride; 
Sigma, St Louis, MO, USA) in $0.05 \%$ Tween 80 and those sprayed only with $0.05 \%$ Tween 80 were used as the control. Each plant was sprayed with $40 \mathrm{ml}$ of the solution in total to ensure even and complete coating of the plant with paraquat.

All experiments were conducted thrice, using samples in triplicates. The data are presented as the mean \pm standard deviation of the three replicates. Differences among groups were evaluated by ANOVA using the Statistical Analysis Software (SAS) version 9.4 (SAS Inc., Cary, USA).

\section{Results and Discussion}

By silencing the NbPDS gene, its role in the differential accumulation of free amino acids and tolerance of the plants to variations in oxidative stress was identified. Due to silencing of the NbPDS gene, as confirmed by the semi-quantitative RT-PCR (data not shown), and a consequential reduction of PDS enzyme, the NbPDS-silenced $N$. benthamiana demonstrated a photo-bleached phenotype and retarded growth (Figs 1 and 2). As the loss of PDS activity led to the accumulation of phytoene in the white tissues of Arabidopsis immutans mutants and blocking of the carotenogenesis step (Wstzel et al. 1994), that diminished levels of carotenoids also resulted in the characteristic photobleaching phenotype observed in $N b P D S$-silenced $N$. benthamiana were elucidated

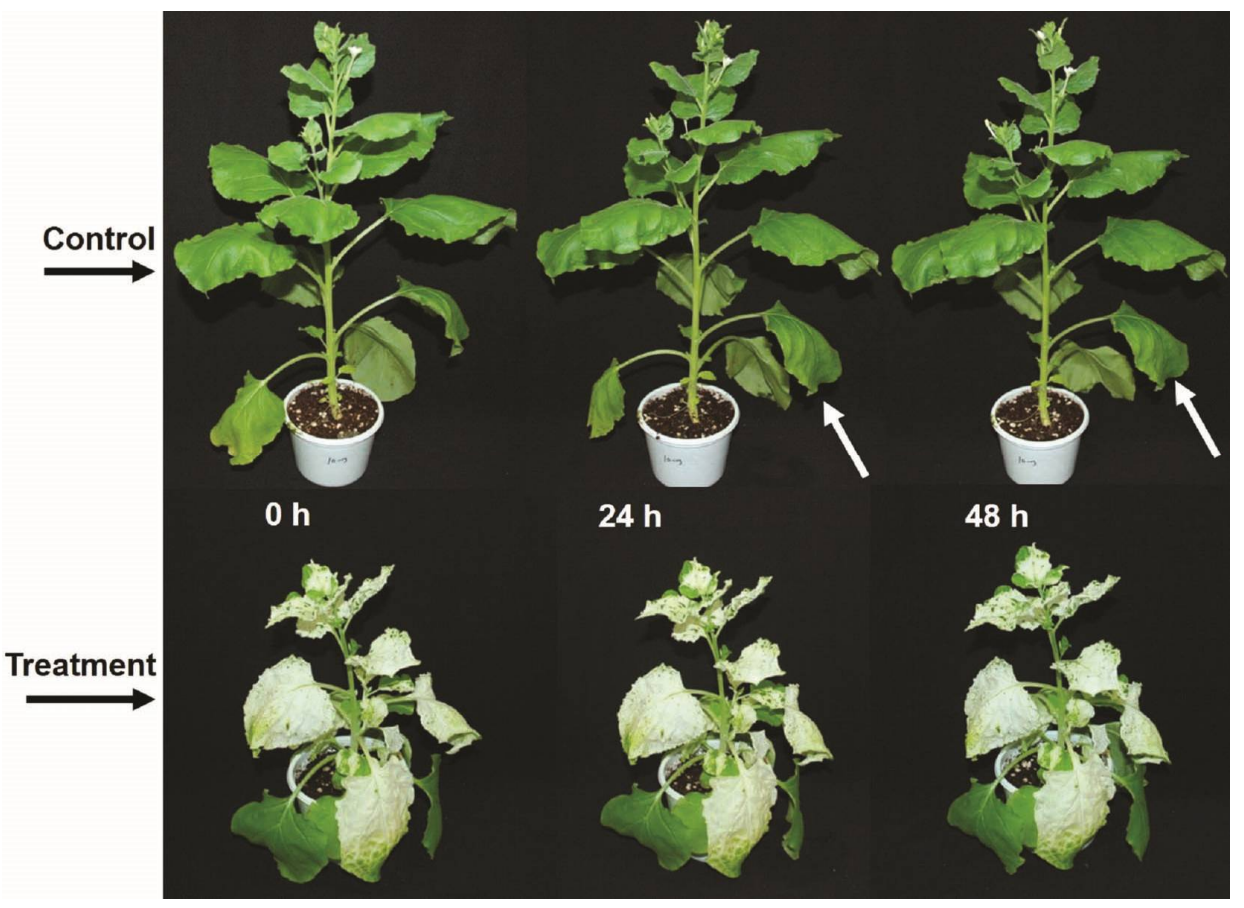

Fig. 1. The GFP- and NbPDS-silenced N. benthamiana sprayed with $10 \mu \mathrm{M}$ paraquat. Arrows indicate injuries caused by paraquat treatment. Injured leaves showed burning symptoms on the leaves. Pictures of the plants were taken 24 and $48 \mathrm{hrs}$ after treatment with $10 \mu \mathrm{M}$ paraquat.

The levels of free amino acids and total soluble proteins were analyzed in the NbPDS-silenced plants. Compared to the control plants, the profile of free amino acid contents in NbPDS-silenced $N$. benthamiana was significantly different, and found to be greater by 9.5 -folds (Table 1, Fig. 3a). It was found that, upon $N b P D S$-silencing, the amount of accumulation of polar positively charged 
amino acids such as lysine, histidine and arginine was the highest. A maximum increase in the amount of accumulated arginine was observed, which was 89.2-folds higher than that of the control plant (Table 1). The polar uncharged amino acids such as serine and threonine demonstrated the second-highest accumulation amounts resulting from the $N b P D S$-silencing. In contrast to the enhanced accumulation potential of free amino acids, the amount of total soluble proteins in $N b P D S$-silenced $N$. benthamiana was lower, only 59.6\%, compared to that of the control plants (Fig. 3b).

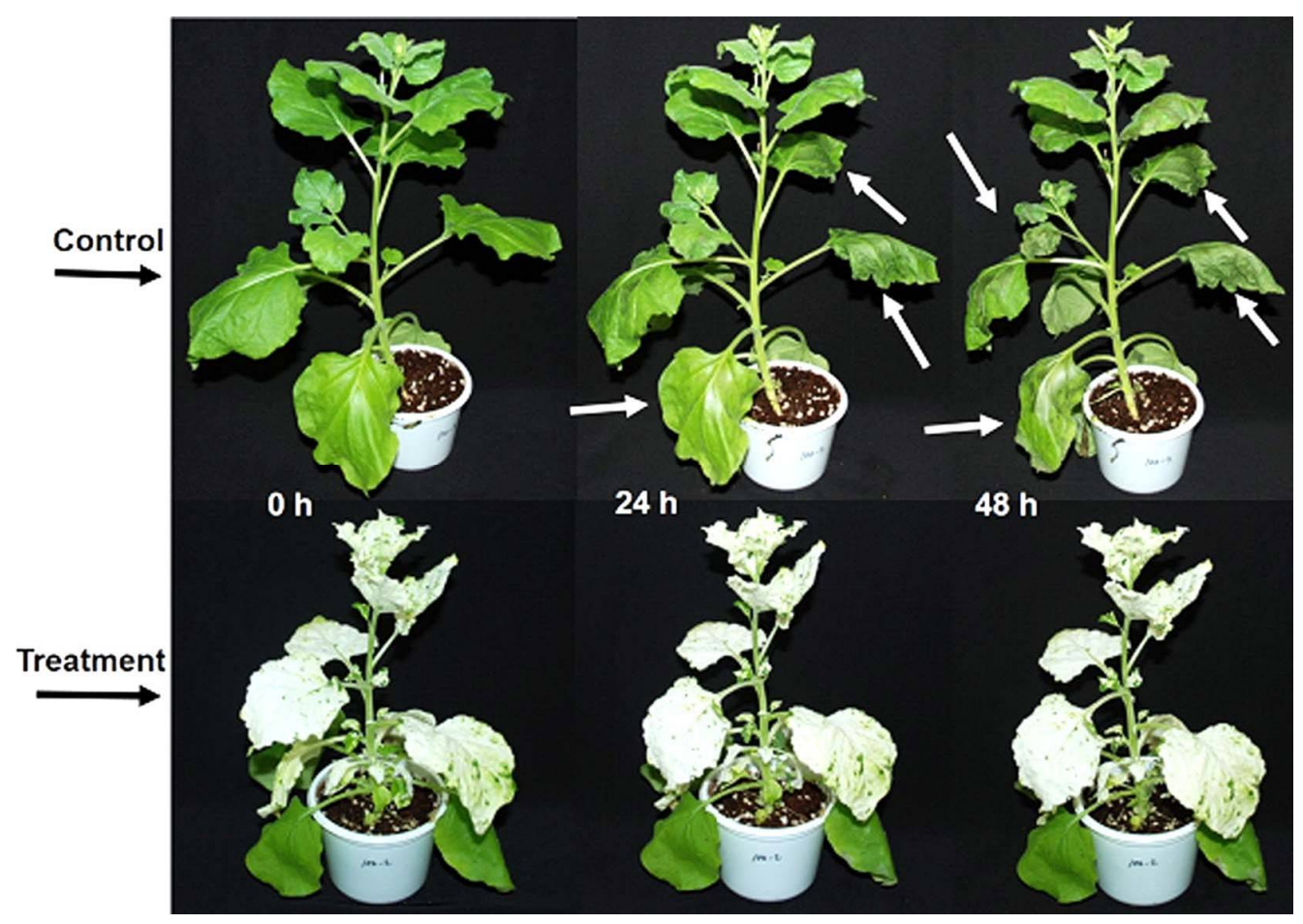

Fig. 2. The GFP- and NbPDS-silenced N. benthamiana sprayed with $100 \mu \mathrm{M}$ paraquat. Arrows indicate injuries caused by paraquat treatment. Injured leaves showed burning symptoms on the leaves. Pictures of the plants were taken 24 and $48 \mathrm{hrs}$ after treatment with $100 \mu \mathrm{M}$ paraquat.

The ROS-generating compound paraquat was used to investigate the response of NbPDSsilenced plants to oxidative stress. Treatment with both 10 and $100 \mu \mathrm{M}$ paraquat injured the control, and the extent of injury was particularly severe in plants subjected to the $100 \mu \mathrm{M}$ concentration (Figs 1 and 2). Contrarily, no severe symptoms of injury were observed in the NbPDS-silenced plants subjected to both 10 and $100 \mu \mathrm{M}$ paraquat spraying (Figs 1 and 2). Paraquat inhibits electron transport and $\mathrm{CO}_{2}$ assimilation in the cells and also triggers the production of ROS, thereby disrupting cellular structures and inhibiting cell growth (Qian et al. 2009). The immutans (im) mutants of Arabidopsis were more tolerant to oxidative stress due to the presence of abnormal chloroplasts lacking colored carotenoids in their white leaf tissues, formed as a result of a defect in the phytoene desaturase activity (Aluru et al. 2009). Although diminished amounts of carotenoids were evident in the photobleached white tissue in both the cases, it is not indicative of increased oxidative stress because carotenoids are antioxidant compounds. Therefore, 
in the present study, significantly high concentrations of free amino acids due to $N b P D S$-silencing can increase the tolerance of silenced plants to oxidative stress and protect them from injury after paraquat spraying.

Table 1. The contents of the amino acids in the 6th leaf of $N$. benthamiana silenced with the GFP gene or NbPDS gene.

\begin{tabular}{|c|c|c|c|}
\hline \multirow{2}{*}{$\begin{array}{l}\text { Amino } \\
\text { acids }\end{array}$} & \multicolumn{2}{|c|}{ Concentration $(\mu \mathrm{g} / \mathrm{g} \mathrm{dw})$} & \multirow{2}{*}{ Ratio (folds) } \\
\hline & $G F P$-silenced & $P D S$-silenced & \\
\hline \multicolumn{4}{|c|}{ Nonpolar aliphatic } \\
\hline Glycine & $0.5 \pm 0.1 b^{\mathrm{z}}$ & $1.5 \pm 0.1 \mathrm{a}$ & 2.9 \\
\hline Alanine & $2.0 \pm 0.3 b$ & $19.0 \pm 5.0 \mathrm{a}$ & 9.7 \\
\hline Proline & $11.0 \pm 5.4 b$ & $40.9 \pm 20.1 \mathrm{a}$ & 3.7 \\
\hline Valine & ND & $23.2 \pm 1.1$ & \\
\hline Leucine & $1.7 \pm 0.1 b$ & $22.3 \pm 1.4 \mathrm{a}$ & 13.2 \\
\hline Isoleucine & $1.0 \pm 0.2 b$ & $12.6 \pm 1.1 \mathrm{a}$ & 12.3 \\
\hline Methionine & $0.7 \pm 0.0 \mathrm{a}$ & $1.0 \pm 0.9 \mathrm{a}$ & 1.5 \\
\hline \multicolumn{4}{|c|}{ Nonpolar aromatic } \\
\hline Phenylalanine & $1.2 \pm 0.3 b$ & $2.3 \pm 0.5 \mathrm{a}$ & 1.9 \\
\hline Tyrosine & $0.9 \pm 0.0 \mathrm{~b}$ & $11.1 \pm 0.7 \mathrm{a}$ & 12.8 \\
\hline \multicolumn{4}{|c|}{ Polar uncharged } \\
\hline Serine & $1.3 \pm 0.2 b$ & $24.1 \pm 2.4 \mathrm{a}$ & 19.2 \\
\hline Threonine & $1.6 \pm 0.3 b$ & $17.3 \pm 0.7 \mathrm{a}$ & 10.9 \\
\hline \multicolumn{4}{|c|}{ Polar positively charged } \\
\hline Lysine & $0.9 \pm 0.1 b$ & $18.3 \pm 1.6 \mathrm{a}$ & 19.3 \\
\hline Histidine & $0.2 \pm 0.1 b$ & $10.2 \pm 1.4 \mathrm{a}$ & 58.1 \\
\hline Arginine & $0.3 \pm 0.1 b$ & $31.0 \pm 4.4 \mathrm{a}$ & 89.2 \\
\hline \multicolumn{4}{|c|}{ Polar negatively charged } \\
\hline Aspartate & $13.0 \pm 1.6 b$ & $150.0 \pm 3.6 \mathrm{a}$ & 11.5 \\
\hline Glutamate & $2.7 \pm 1.3 b$ & $36.1 \pm 4.0 \mathrm{a}$ & 13.3 \\
\hline \multicolumn{4}{|l|}{ Non-protein } \\
\hline GABA & $13.0 \pm 1.6 b$ & $72.4 \pm 10.3 \mathrm{a}$ & 5.6 \\
\hline Total & $52.0 \pm 9.6 b$ & $493.4 \pm 32.8 \mathrm{a}$ & 9.5 \\
\hline
\end{tabular}

${ }^{\mathrm{z}}$ Different letters in the same row indicate a significant difference $(p<0.05)$. ND: not detected.

After $24 \mathrm{hrs}, N b P D S$-silenced plants subjected to $10 \mu \mathrm{M}$ paraquat treatment accumulated 10.4-folds higher levels of total free amino acids and $81.5 \%$ total soluble proteins than those of the control (Table 2, Fig. 3c and d). After 24 hrs, in NbPDS-silenced $N$. benthamiana subjected to 100 $\mu \mathrm{M}$ paraquat treatment, the content of total free amino acids and total soluble proteins was 6.9 fold higher and $56.1 \%$ compared to that of the control, respectively (Table 3, Fig. 3c and d). After $48 \mathrm{hrs}, \mathrm{NbPDS}$-silenced plants subjected to 10 and $100 \mu \mathrm{M}$ paraquat treatment contained 63.3 and $73.8 \%$ total soluble protein contents compared to those of the controls, respectively (Fig. 3e).

In the controls, paraquat treatment significantly changed the contents of free amino acids such as arginine. Due to the changes in the levels of amino acids by paraquat treatment, the ratio of increase of the amino acid content in the $N b P D S$-silenced plants to that of the control at $0 \mathrm{hr}$ was 9.5-fold (Table 1), whereas those of plants treated with 10 and $100 \mu \mathrm{M}$ paraquat at $24 \mathrm{hrs}$ was 
10.4- and 6.9-folds, respectively (Tables 2 and 3). This indicates that $100 \mu \mathrm{M}$ paraquat treatment induced severe injury in the controls increasing their content of free amino acids but did not induce damage in the $N b P D S$-silenced plants, which were protected by the presence of high levels of the free amino acids. As reported previously, increase in the levels of free amino acids can provide resistance to plants under conditions of both abiotic and biotic stresses (Hildebrandt et al. 2015). Free amino acids accumulated due to $N b P D S$-silencing may contribute in increasing the plant tolerance to oxidative stress under normal growth conditions and upon paraquat treatment.

Table 2. The contents of the amino acids in the 6th leaf of $N$. benthamiana silenced with the $G F P$ gene or the $N b P D S$ gene after $24 \mathrm{hrs}$ of $10 \mu \mathrm{M}$ paraquat treatment.

\begin{tabular}{|c|c|c|c|}
\hline \multirow{2}{*}{$\begin{array}{l}\text { Amino } \\
\text { acids }\end{array}$} & \multicolumn{2}{|c|}{ Concentration $(\mu \mathrm{g} / \mathrm{g} \mathrm{dw})$} & \multirow{2}{*}{ Ratio (folds) } \\
\hline & $G F P$-silenced & $P D S$-silenced & \\
\hline \multicolumn{4}{|c|}{ Nonpolar aliphatic } \\
\hline Glycine & $0.5 \pm 0.1 b^{\mathrm{z}}$ & $1.4 \pm 0.2 \mathrm{a}$ & 3.0 \\
\hline Alanine & $2.1 \pm 0.3 b$ & $22.1 \pm 6.1 \mathrm{a}$ & 10.3 \\
\hline Proline & $8.5 \pm 1.6 b$ & $36.2 \pm 7.2 \mathrm{a}$ & 4.3 \\
\hline Valine & $1.7 \pm 0.3 b$ & $28.2 \pm 4.4 \mathrm{a}$ & 16.6 \\
\hline Leucine & $1.7 \pm 0.5 b$ & $27.3 \pm 5.9 a$ & 16.0 \\
\hline Isoleucine & $1.2 \pm 0.2 b$ & $17.5 \pm 3.3 \mathrm{a}$ & 14.9 \\
\hline Methionine & $0.5 \pm 0.1 b$ & $1.6 \pm 0.6 \mathrm{a}$ & 3.3 \\
\hline \multicolumn{4}{|c|}{ Nonpolar aromatic } \\
\hline Phenylalanine & $0.9 \pm 0.4 b$ & $2.7 \pm 0.3 \mathrm{a}$ & 3.0 \\
\hline Tyrosine & $0.8 \pm 0.3 b$ & $13.4 \pm 4.2 \mathrm{a}$ & 16.8 \\
\hline \multicolumn{4}{|c|}{ Polar uncharged } \\
\hline Serine & $1.5 \pm 0.4 b$ & $32.3 \pm 8.5 \mathrm{a}$ & 21.0 \\
\hline Threonine & $1.6 \pm 0.3 b$ & $20.3 \pm 4.4 \mathrm{a}$ & 13.1 \\
\hline \multicolumn{4}{|c|}{ Polar positively charged } \\
\hline Lysine & $1.1 \pm 0.3 b$ & $18.5 \pm 4.5 \mathrm{a}$ & 16.7 \\
\hline Histidine & $0.4 \pm 0.1 b$ & $11.1 \pm 2.2 \mathrm{a}$ & 25.9 \\
\hline Arginine & $0.3 \pm 0.1 b$ & $33.5 \pm 6.4 \mathrm{a}$ & 99.1 \\
\hline \multicolumn{4}{|c|}{ Polar negatively charged } \\
\hline Aspartate & $13.1 \pm 1.5 b$ & $153.6 \pm 16.9 \mathrm{a}$ & 11.7 \\
\hline Glutamate & $3.3 \pm 1.1 b$ & $38.3 \pm 3.2 \mathrm{a}$ & 11.6 \\
\hline \multicolumn{4}{|l|}{ Non-protein } \\
\hline GABA & $11.1 \pm 1.2 b$ & $66.8 \pm 13.9 \mathrm{a}$ & 6.0 \\
\hline Total & $50.4 \pm 5.4 b$ & $524.9 \pm 56.0 \mathrm{a}$ & 10.4 \\
\hline
\end{tabular}

${ }^{\mathrm{z}}$ Different letters in the same row indicate a significant difference $(\mathrm{p}<0.05)$.

Total soluble protein contents in the $N b P D S$-silenced plants were significantly lower than those of the control (Fig. 3b). From 24 to $48 \mathrm{hrs,} \mathrm{the} \mathrm{ratio} \mathrm{of} \mathrm{total} \mathrm{protein} \mathrm{contents} \mathrm{in} \mathrm{the} \mathrm{control} \mathrm{to} \mathrm{the}$ NbPDS-silenced plants sprayed with $10 \mu \mathrm{M}$ paraquat decreased from 81.5 to $63.3 \%$, whereas, that of the plants subjected to $100 \mu \mathrm{M}$ paraquat treatment increased from 56.1 to $73.8 \%$. All data indicated that a considerable quantity of free amino acids might not have been incorporated into the proteins in the $N b P D S$-silenced $N$. benthamiana, but ironically, the increased content of total 
free amino acids reduced injury by oxidative stress, as indicated by reduced total soluble protein contents.

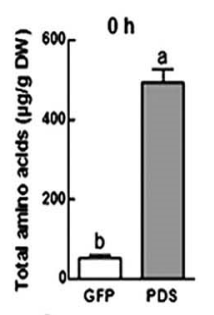

a
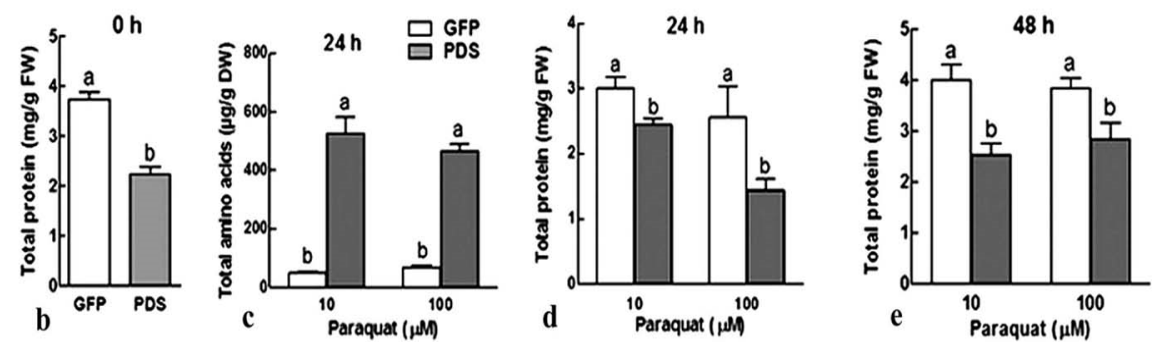

Fig. 3. Amounts of total free amino acids and total soluble proteins in leaves of GFP-silenced control and NbPDS-silenced N. benthamiana. (a) Total amino acids and (b) total soluble proteins from GFP- and NbPDS-silenced plants without paraquat treatment. (c) Total amino acids and (d) total soluble proteins after $24 \mathrm{hrs}$ of paraquat treatment. (e) Total soluble proteins after $48 \mathrm{hrs}$ of paraquat treatment. Different letters on bars indicate significant differences at $\mathrm{p}<0.05$.

Table 3. The contents of the amino acids in the 6th leaf of $N$. benthamiana silenced with the GFP gene or $N b P D S$ gene after $24 \mathrm{hrs}$ of $100 \mu \mathrm{M}$ paraquat treatment.

\begin{tabular}{|c|c|c|c|}
\hline \multirow{2}{*}{$\begin{array}{l}\text { Amino } \\
\text { acids }\end{array}$} & \multicolumn{2}{|c|}{ Concentration $(\mu \mathrm{g} / \mathrm{g} \mathrm{dw})$} & \multirow{2}{*}{ Ratio (folds) } \\
\hline & $G F P$-silenced & $P D S$-silenced & \\
\hline \multicolumn{4}{|c|}{ Nonpolar aliphatic } \\
\hline Glycine & $0.5 \pm 0.1 b^{z}$ & $1.5 \pm 0.1 \mathrm{a}$ & 3.2 \\
\hline Alanine & $6.4 \pm 0.3 b$ & $16.5 \pm 0.9 \mathrm{a}$ & 2.6 \\
\hline Proline & $10.7 \pm 1.9 \mathrm{~b}$ & $18.1 \pm 9.5 \mathrm{a}$ & 1.7 \\
\hline Valine & $2.0 \pm 1.8 \mathrm{~b}$ & $28.0 \pm 2.2 \mathrm{a}$ & 13.7 \\
\hline Leucine & $3.2 \pm 0.7 b$ & $26.8 \pm 4.0 \mathrm{a}$ & 8.5 \\
\hline Isoleucine & $2.1 \pm 0.6 b$ & $16.7 \pm 1.3 \mathrm{a}$ & 7.9 \\
\hline Methionine & $0.4 \pm 0.1$ & ND & \\
\hline \multicolumn{4}{|c|}{ Nonpolar aromatic } \\
\hline Phenylalanine & $1.3 \pm 0.1 b$ & $2.8 \pm 0.4 a$ & 2.1 \\
\hline Tyrosine & $1.4 \pm 0.2 b$ & $15.6 \pm 1.1 \mathrm{a}$ & 11.5 \\
\hline \multicolumn{4}{|c|}{ Polar uncharged } \\
\hline Serine & $2.7 \pm 0.5 b$ & $30.6 \pm 0.8 \mathrm{a}$ & 11.3 \\
\hline Threonine & $2.6 \pm 0.4 b$ & $19.3 \pm 2.7 \mathrm{a}$ & 7.5 \\
\hline \multicolumn{4}{|c|}{ Polar positively charged } \\
\hline Lysine & $2.0 \pm 0.2 b$ & $20.7 \pm 3.3 \mathrm{a}$ & 10.3 \\
\hline Histidine & $0.6 \pm 0.3 b$ & $12.6 \pm 2.0 \mathrm{a}$ & 21.8 \\
\hline Arginine & $1.1 \pm 0.7 b$ & $36.2 \pm 10.1 \mathrm{a}$ & 34.4 \\
\hline \multicolumn{4}{|c|}{ Polar negatively charged } \\
\hline Aspartate & $15.5 \pm 5.3 b$ & $144.7 \pm 20.7 \mathrm{a}$ & 9.3 \\
\hline Glutamate & $3.4 \pm 1.3 b$ & $29.8 \pm 2.6 \mathrm{a}$ & 8.7 \\
\hline \multicolumn{4}{|l|}{ Non-protein } \\
\hline GABA & $11.5 \pm 1.5 \mathrm{~b}$ & $47.5 \pm 6.9 \mathrm{a}$ & 4.1 \\
\hline Total & $67.5 \pm 10.4 b$ & $467.5 \pm 21.2 \mathrm{a}$ & 6.9 \\
\hline
\end{tabular}

${ }^{2}$ Different letters in the same row indicate a significant difference $(p<0.05)$. ND: not detected. 
The present study identified that silencing of the NbPDS gene in $N$. benthamiana produced albinism in the plants but increased the content of their free amino acids and their capacity to withstand severe oxidative stress. Silencing the PDS gene induced a phenotypic disadvantage by the manifestation of dwarfism and albinism, but alternatively increased the amount of free amino acids which can mitigate the oxidative stress conditions and possibly be used for amino acid capsule formation.

\section{Acknowledgments}

This study was supported by the Basic Science Research Program through the National Research Foundation of Korea (NRF) funded by the Ministry of Education (NRF2019R1F1A1052625).

\section{References}

Abogadallah GM 2010. Insights into the significance of antioxidative defense under salt stress. Plant Signal. Behav. 5: 369-374.

Ademowo OS, Dias HKI, Burton DGA and Griffiths HR 2017. Lipid (per) oxidation in mitochondria: An emerging target in the ageing process? Biogerontology 18: 859-879.

Ali MS, Kim KW, Dhakal R, Choi D and Baek KH 2015. Accumulation of high contents of free amino acids in the leaves of Nicotiana benthamiana by the co-suppression of $\mathrm{NbClpCl}$ and $\mathrm{NbClpC2}$ genes. Plant Cell Rep. 1: 355-365.

Aluru MR, Zola J, Foudree A and Rodermel SR 2009. Chloroplast photooxidation-induced transcriptome reprogramming in Arabidopsis immutans white leaf sectors. Plant Physiol. 150: 904-923.

Anaraki ZE, Shariati M and Tafreshi SAH 2017. Transient silencing of phytoene desaturase reveals critical roles on plant response to salinity stress. Acta Physiol. Plant 39: 1-15.

Brausemann A, Gemmecker S, Koschmieder J, Ghisla S, Beyer P and Einsle O 2017. Structure of phytoene desaturase provides insights into herbicide binding and reaction mechanisms involved in carotene desaturation. Structure 25: 1222-1232.

Halliwell B 2006. Reactive species and antioxidants. Redox biology is a fundamental theme of aerobic life. Plant Physiol. 141: 312-322.

Hasan MM, Kim HS, Jeon JH, Kim SH, Moon B, Song JY, Shim SH and Baek KH 2014. Metabolic engineering of Nicotiana benthamiana for the increased production of taxadiene. Plant Cell Rep. $33: 895-904$

Hildebrandt TM, Nunes NA, Araújo WL and Braun HP 2015. Amino acid catabolism in plants. Mol. Plant 8: 1563-1579.

Kanojia A and Dijkwel PP 2018. Abiotic stress responses are governed by reactive oxygen species and age. Ann. Plant Rev. 1: 1-32.

Liang W, Ma X, Wan P and Liu L 2018. Plant salt-tolerance mechanism: A review. Biochem. Bioph. Res. Co. 495: 286-291.

Nisar N, Li L, Lu S, Khin NC and Pogson BJ 2015. Carotenoid metabolism in plants. Mol. Plant 8: 68-82.

Pandey S, Fartyal D, Agarwal A, Shukla T, James D, Kaul T, Negi YK, Arora S and Reddy MK 2017. Abiotic stress tolerance in plants: Myriad roles of ascorbate peroxidase. Front. Plant Sci. 8: 1-13.

Qian H, Sun L, Liu W, Chen W, Fu Z and Jin Y 2009. Inhibitory effects of paraquat on photosynthesis and the response to oxidative stress in Chlorella vulgaris. Ecotoxicology 18: 537-543.

Ramel F, Mialoundama AS and Havaux M 2013. Nonenzymic carotenoid oxidation and photooxidative stress signalling in plants. J. Expt. Bot. 64: 799-805.

Sakamoto A and Murata N 2000. Genetic engineering of glycinebetaine synthesis in plants: Current status and implications for enhancement of stress tolerance. J. Exp. Bot. 51: 81-88. 
Soares C, Carvalho MEA, Azevedo RA and Fidalgo F 2018. Plants facing oxidative challenges - A little help from the antioxidant networks. Environ. Exp. Bot. 161: 4-25.

Srinivasan R, Babu S and Gothandam KM 2017. Accumulation of phytoene, a colorless carotenoid by inhibition of phytoene desaturase (PDS) gene in Dunaliella salina V-101. Bioresource Technol. 242: 311-318.

Sun T, Yuan H, Cao H, Yazdani M, Tadmor Y and Li L 2018. Carotenoid metabolism in plants: The role of plastids. Mol. Plant 11: 58-74.

Wstzel C, Jiang CZ, Meehan LJ, Voytas DF and Rodermel SR 1994. Nuclear-organelle interactions: The immutans variegation mutant of Arabidopsis is plastid autonomous and impaired in carotenoid biosynthesis. Plant J. 6: 161-175.

Xie X, He Z, Chen N, Tang Z, Wang Q and Cai Y 2019. The roles of environmental factors in regulation of oxidative stress in plant. Biomed Res. Int. 2019: 1-11.

(Manuscript received on 30 April, 2019, revised on 11 February, 2020) 